\title{
Relationship between anxiety, depression and quality of life with the intensity of reflex sweating after thoracoscopic sympathectomy for treatment of primary hyperhidrosis
}

\section{Relação entre ansiedade, depressão e qualidade de vida com a intensidade da sudorese reflexa após simpatectomia torácica por videocirurgia para tratamento da hiperidrose primária}

luciara Irene de Nadai Dias'; Eliana Cristina Martins Miranda²; Ivan Felizardo Contrera Toro'; Ricardo Kalaf Mussi”.

\begin{abstract}
A B S T R A C T
Objective: to compare the intensity of reflex sweating with the degree of anxiety and its interference in the quality of life of patients undergoing Thoracoscopic (VATS) sympathectomy in the pre- and postoperative period. Methods: we evaluated 54 patients with a mean age of 26 years (16-49 years) undergoing sympathectomy in the R3-R4 level. We applied two questionnaires at three different times: "Quality of life in patients with primary hyperhidrosis" and "Scale for anxiety and depression". Results: of the patients studied, 93\% showed significant improvement in quality of life 30 days after surgery, the effects remaining after six months. There were no postoperative complications. The patient's level of anxiety is highly correlated with the intensity of reflex sweating after 30 and 180 days. Conclusion: Thoracoscopic sympathectomy improves quality of life of patients with primary hyperhidrosis, even with the emergence of reflex sweating. Anxiety directly relates to the intensity of reflex sweating, without compromising the degree of patient satisfaction.
\end{abstract}

Keywords: Hyperhidrosis. Quality of Life. Anxiety. Sympathectomy. Thoracic Surgery, Video-Assisted.

\section{INTRODUCTION}

Drim rimary hyperhidrosis (PH) is a clinical condition defined as sweating, localized excessive, which mainly affects the hands, armpits, feet and face. It has unknown etiology, occurring due to hyperactivity of the sympathetic nervous system. The literature reports an incidence of $1 \%$ and it is more frequent in young adult patients ${ }^{1}$.

Currently the first choice therapy, and the providing better outcomes in $\mathrm{PH}$ treatment, is the thoracoscopic sympathectomy ${ }^{2,3}$. Its most common side effect is the reflex sweating (RS), characterized by increased sweating in other parts of the body such as the back, abdomen and thighs ${ }^{4}$.

The use of scores allows for better quality and refinement of diagnostic assessments and/or monitoring of patients in clinical trials ${ }^{5}$.

The literature extensively discusses the relationship between RS intensity and the adopted surgical level², but few studies have correlated this side effect with the degree of anxiety and depression and the quality of life in patients undergoing thoracoscopic sympathectomy.

\section{METHODS}

This was a prospective cohort study conducted between January 2010 and September 2013 in the Department of Thoracic Surgery, State University of Campinas (UNICAMP), Brazil. We analyzed $54 \mathrm{PH}$ patients of both genders, aged between 16 and 70 years, submitted to thoracoscopic sympathectomy, the surgery being performed in the R3-R4 levels for all the different sweating sites.

Participants responded to the questionnaires on quality of life and anxiety in the preoperative period and 30 and 180 days after surgery. To evaluate the quality of life of patients with $\mathrm{PH}$, we applied the "Quality of Life Questionnaire in Patients with Primary hyperhidrosis"1.

1 - Post-graduate Program in Surgery Sciences, Faculty of Medical Sciences, Campinas State University (Unicamp), Campinas, SP, Brazil. 2 - Post-graduate Program in Internal Medicine, Faculty of Medical Sciences, Campinas State University (Unicamp), Campinas, SP, Brazil. 
Table 1. Sites of primary Hyperhidrosis

\begin{tabular}{|c|c|}
\hline Sites of involvement & $\%$ \\
\hline Hands and armpits & 54 \\
\hline Hands, armpits and feet & 28 \\
\hline Armpits & 9 \\
\hline Hands and feet & 5 \\
\hline Hands & 4 \\
\hline Total & 100.0 \\
\hline
\end{tabular}

The questionnaire consists of 20 questions divided into five domains. The higher the score, the worse the patient's quality of life. Each domain contains different levels of responses based on tables that admit only one answer. The difference between the pre and postoperative assessment is considered the treatment effect on quality of life'.

Regarding the anxiety of patients with $\mathrm{PH}$, we used the questionnaire "Scale for Anxiety and Depression (HAD)" translated and validated by Botega et al., in $1995^{6}$. This is a self-rating scale consisting of 14 multiple choice questions, requiring approximately four minutes to perform. The patient is requested to respond according to what he/she has felt during the last week ${ }^{6}$. In addition, all participants signed an informed consent form previously approved by the local Ethics in Research Committee.

After 30 and 180 days, we questioned the patient if there was sweating in another location and its intensity: absent (did not develop RS), mild (presented sweating in other areas, without relapse, but not bothersome), moderate (presented sweating in other areas, without recurrence, but it did not hinder usual daily activities) or severe (presented sweating in other areas, without recurrence, and desired treatment).

We carried out the comparisons between the three evaluation periods with respect to the variables quality of life, anxiety and depression using the Friedman test, and when we found a significant difference, we applied the non-parametric Wilcoxon test considering the Bonferroni correction ${ }^{7}$ for multiple comparisons. The $p$ value was considered $<0.01$. For the analyzes of reflex sweating levels with respect to quality of life scores, anxiety and depression during periods 30 and 180 days after surgery, we used the Kruskal-Wallis test, and when necessary, the Dunn post-test, also considering the Bonferroni correction and contemplating the value of $p$ $<0.02$. We used the software the SAS (Statistical Analysis System) version 9.2 .

\section{RESULTS}

We analyzed all 54 patients enrolled in the study, with a median age of 26 years (16-49), of whom $33(61 \%)$ were female. The main localization of excessive sweating was in the hands and armpits (54\%), as shown in Table 1.

Before surgery, $32 \%$ of patients rated their quality of life (QOL) as very bad, $43 \%$ bad, $24 \%$ good and $2 \%$ very good. After 30 days, $87 \%$ of patients rated their quality of life regarding hyperhidrosis as much better, $9 \%$ a little better, $2 \%$ as the same and $2 \%$ as much worse. After six months, $80 \%$ of patients rated their quality of life as much better, 13\% a little better, $5 \%$ as unchanged and $2 \%$ as slightly worse $(p<0.0001)$. Regarding the domains assessed, before surgery they showed statistically significant differences when compared to the domains after 30 or 180 days, reflecting the effect of treatment $(p<0.0001)$, while the domains of QOL within 30 and 180 days did not result in any difference. Table 2 shows the distribution of values for QOL scales, anxiety and depression in the respective analyzed times and their $p$ values.

As for the classification of reflex sweating after 30 days, its frequency was: mild in 24 cases (44\%); moderate in 19 (35\%); intense in 10 (18\%) and only one (2\%) individual denied having RS in any period. After 180 days, 16 (30\%) classified it as mild; 21 (39\%) moderate 
Table 2. Comparison of QOL versus anxiety and depression at different times

\begin{tabular}{lccccccccc}
\hline & \multicolumn{3}{c}{ Quality of life } & \multicolumn{3}{c}{ Anxiety } & \multicolumn{3}{c}{ Depression } \\
& Before & $30 \mathrm{~d}$ & $180 \mathrm{~d}$ & Before & $30 \mathrm{~d}$ & $180 \mathrm{~d}$ & Before & $30 \mathrm{~d}$ & $180 \mathrm{~d}$ \\
\hline Median & 83.0 & 20.5 & 20.0 & 6.0 & 6.0 & 6.0 & 3.0 & 2.0 & 2.5 \\
Range & $49-100$ & $20-95$ & $20-91$ & $1-6$ & $0-18$ & $0-18$ & $0-19$ & $0-20$ & $0-13$ \\
Average & 80.4 & 27.3 & 25.2 & 7.1 & 6.2 & 6.9 & 3.5 & 3.4 & 3.2 \\
SD & \pm 13.9 & \pm 12.7 & \pm 11.8 & \pm 4.4 & \pm 4.1 & \pm 4.51 & \pm 3.6 & \pm 3.7 & \pm 3.2 \\
p-value * & & $<0,0001$ & & & 0.30 & & & 0.89 & \\
\hline
\end{tabular}

* $p$ values obtained through the Friedman test.

and $16(30 \%)$ intense, showing increase in cases of severe sweating $(p<0.0001)$ in the late postoperative period. There was no recurrence, in any individual, in the hands, armpits or feet. The sites mentioned with reflex sweating were thighs, abdomen and back.

Table 3 makes possible to identify the changes in classification referred to by patients after 30 and 180 days after surgery, as well as the absence of symptoms in one individual.

By analyzing the distribution of reflex sweating rating with the quality of life of patients and the level of anxiety and depression after 30 and 180 days, we found a significant difference in the intensity of sweating with the anxiety level (Figures 1 and 2). On the other hand, the comparison between the different domains of QOL and the rates of depression were not significant.

\section{DISCUSSION}

Currently, quality of life questionnaires have been highlighted as an important tool to assess results in medicine, as psychosocial factors may result in better patients' management ${ }^{4}$. In this study we applied the quality of life questionnaire for individuals with specific $\mathrm{PH}$, allowing a careful analysis of these patients' quality of life. Furthermore, we used a questionnaire to assess the intensity of anxiety and depression, aiming to verify the presence and magnitude of these disorders in our sample.

Clinical symptoms lead to consider PH's diagnosis as a psychiatric disorder, with some studies characterizing such individuals as anxious ${ }^{8,9}$. In our study, patients reported excessive fear and embarrassment, anxiety features known as social phobia.

Table 3. Reflex sweating intensity 30 and 180 days after surgery

\begin{tabular}{lccc}
\hline \multicolumn{1}{c}{ Sweating } & Period & $\mathrm{n}$ & $\%$ \\
\hline Mild & 30 days & 24 & 44.45 \\
Moderate & & 10 & 18.51 \\
Severe & 19 & 35.19 \\
Absent & 1 & 1.85 \\
Total & & 54 & 100.00 \\
\hline & 180 days & 16 & 29.63 \\
Mild & & 16 & 29.63 \\
Moderate & 21 & 38.89 \\
Severe & & 1 & 1.85 \\
Absent & & 54 & 100.00 \\
Total & & & \\
\hline
\end{tabular}




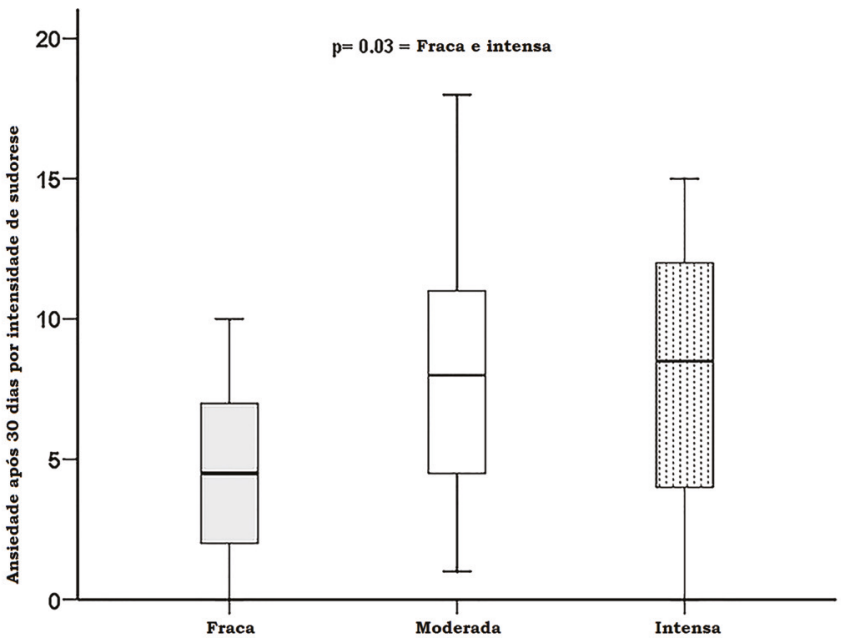

Figure 1. Anxiety level stratified b reflex y sweating 30 days after surgery.

Before surgery, patients were very committed to participating in the study due to the problem presented, ie, excessive sweat that bothered so much. After 30 days, they found themselves happy, with high self-esteem due to the initial improvement and the positive impact that surgery performed in their lives, and still willing to collaborate, responding calmly to the questionnaires, on request. However, after six months, with the problem solved, ie, hands and armpits dry as part of the routine, there was a greater resistance to cooperation with this study regarding the questionnaires. At this time of the postoperative period, even with full return to daily activities, it was possible to correlate the rise in anxiety level with the most intense sweating reflex, and slight decrease in quality of life. The evaluation after 30 days already presented evidence that the rate of anxiety was related to the intensity of RS, being confirmed in the evaluation after 180 days, showing that the higher the level of anxiety, the greater the RS intensity.

$\mathrm{PH}$ may be associated with significant impairment in patients' quality of life, interfering with social and professional activities ${ }^{8,10}$. Wolosker et al. ${ }^{4}$ demonstrated that the quality of life of individuals with $\mathrm{PH}$ is severely diminished, though not at risk of death. These authors add that, in some cases, not only anxiety, stress and apprehension are present, but also risks in professional activities, such as police handling weapons and electricians. They observed that the preoperative quality of life was significantly affected by the presence of abundant sweating in the hands, armpits and/

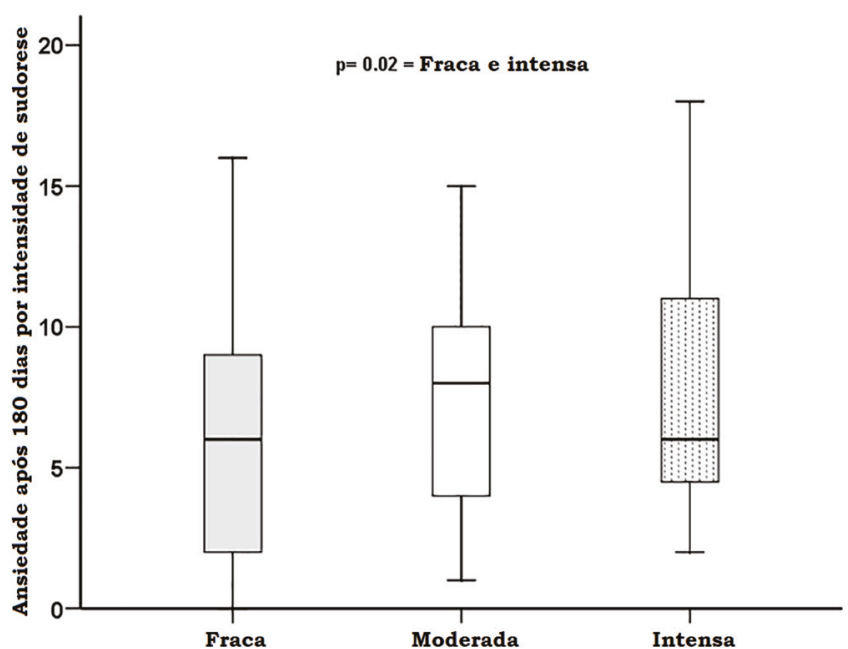

Figure 2. Anxiety level stratified by reflex sweating 180 days after surgery.

or feet.

Primary hyperhidrosis and anxiety seem to have a complex relationship ${ }^{11}$. Excessive sweating, especially in the hands, is accompanied by a high degree of anxiety and sympathetic overactivity ${ }^{4,12}$. This study demonstrated the presence of anxiety both in the pre and postoperative periods, sometimes at high levels, suggesting the need for medical/psychological evaluation and support.

Reflex sweating is the main side effect of sympathectomy. It comprises episodes of sweating in other body parts that were not common before surgery. It usually occurs in the back, legs, abdomen, thighs, groin, feet and butocks ${ }^{13}$. The signs and symptoms start soon after surgery and may worsen with the climate and/or psychological and emotional fluctuations ${ }^{14}$. This side effect appeared in the 30-day postoperative evaluation in 53 cases, with main complaints in the back, abdomen and thighs. Lyra et al. ${ }^{15}$ describe the need for psychological support and claim that the reflex sweating resembles $\mathrm{PH}$, being induced by mental stress or anxiety.

One can also observe significant improvement in patients' quality of life 30 days after surgery, such result being persistent after 180 days. Moreover, the improvement of quality of life related to the intensity of reflex sweating over time showed that the results were significantly better not only till the thirtieth day after the surgery, but also after 180 days, though with a slight decrease at this later time, and directly related to the RS intensity. 
Apparently most patients accept RS well, since they respond to postoperative assessment questionnaires as the operation result being excellent or satisfactory. The study from Stefaniak and Cwigon in $2013^{16}$ shows improvement in the quality of life of more than $90 \%$ of patients after sympathectomy. Of the 54 patients in this study, none regretted having undergone sympathectomy, proving that the RS is preferable to $\mathrm{PH}$, as also demonstrated in the Cardoso et al. ${ }^{3}$. Baroncello et al. ${ }^{17}$ reported that reflex sweating is generally weak in most of patients and does not cause as much social, emotional or professional commitment as primary hyperhidrosis, patients preferring the reflex sweating. In this study, 53 (98\%) of the 54 patients experienced this side effect, reporting that the higher the level of anxiety presented at any given time, the worse the sweating int the reflex sweating sites (abdomen, thighs, back and groin). However, there were no cases of intolerable reflex sweating.

The main disadvantage of this procedure is its potential irreversibility and, therefore, the patient should be fully informed of the possible complications and postoperative side effects ${ }^{2}$.

The qualitative analysis of this group of patients' psychosomatic factors demonstrated in this study will allow other quantitative analyzes, such as different levels of the sympathetic chain blockage or even the extent of the interrupted area, to be better studied.

\title{
R E S U M O
}

\begin{abstract}
Objetivo: avaliar a intensidade de sudorese reflexa com o grau de ansiedade e sua interferência na qualidade de vida de indivíduos submetidos à simpatectomia por videotoracoscopia nos períodos pré e pós-operatório. Métodos: foram avaliados 54 pacientes com média de idade de 26 anos (16 a 49 anos), submetidos à simpatectomia em nível R3-R4. Dois questionários foram aplicados em três momentos diferentes: "Qualidade de vida em pacientes com hiperidrose primária e "Escala para ansiedade e depressão". Resultados: dos pacientes estudados, 93\% mostrou melhora significativa na qualidade de vida após 30 dias da cirurgia, com os efeitos remanescentes após seis meses. Não houve complicações pós-operatórias. A análise mostrou que o nível de ansiedade do paciente é altamente correlacionado com a intensidade da sudorese reflexa após 30 e 180 dias. Conclusão: a simpatectomia torácica por videotoracoscopia melhora a qualidade de vida de pacientes com hiperidrose primária, mesmo com o surgimento de sudorese reflexa. A ansiedade está diretamente relacionada com a intensidade da sudorese reflexa, sem comprometer o grau de satisfação do paciente.
\end{abstract}

Descritores: Hiperidrose. Qualidade de Vida. Ansiedade. Simpatectomia. Cirurgia Torácica Vídeoassistida.

\section{REFERENCES}

1. Campos JRM, Kauffman P, Werebe EC, Andrade Filho LO, Kuzniek S, Wolosker N, et al. Questionário de qualidade de vida em pacientes com hiperidrose primária. J Bras Pneumol. 2003;29(4):178-81.

2. Boscardim PCF, Oliveira RA, Oliveira AAFR, Souza JM, Carvalho RG. Simpatectomia torácica ao nível de $4^{a}$ e $5^{\text {a }}$ costelas para tratamento de hiper-hidrose axilar. J Bras Pneumol. 2011;37(1):6-12.

3. Cardoso PO, Rodrigues KCL, Mendes KM, Petroianu A, Resende M, Alberti LR. Avaliação de pacientes submetidos a tratamento cirúrgico de hiperidrose palmar quanto à qualidade de vida e ao surgimento de hiperidrose compensatória. Rev Col Bras Cir. 2009;36(1):14-8.

4. Wolosker N, de Campos JR, Kauffman P, de Oliveria LA, Munia MA, Jatene FB. Evaluation of quality of life over time among 453 patients with hyperidrosis to endoscopic thoracic sympathectomy. J Vasc Surg. 2012;55(1):154-6.

5. Nardi AE. Comentários do debatedor: escalas de avaliação de ansiedade. Rev Psiq Clin. 1998;(6):331-3.

6. Botega NJ, Bio MR, Zomignani MA, Garcia Jr. C, Pereira WAB. Transtornos do humor em enfermaria de clínica médica e validação de escala de medida (HAD) de ansiedade e depressão. Rev Saúde Pública. 1995;29(5):355-63.

7. Johnson RA, Wichern DW. The Bonferroni method of multiple comparisons. In: Johnson RA, Wichern DW, editors. Applied multivariate statistical analysis.3rd ed. New Jersey: Prentice-Hall. 1992. p.197-9.

8. Davidson JR, Foa EB, Connor KM, Churchill LE. Hyperidrosis in social anxiety disorder. Prog Neuropsychopharmacol Biol Psychiatry. 2002;26(7-8):1327-31.

9. Ramos R, Moya J, Morera R, Masuet C, Perna V, Macia I, et al. An assessment of anxiety in patients with primary 
hyperhidrosis before and after endoscopic thoracic sympathicolysis. Eur J Cardiothorac Surg. 2006;30(2):228-31.

10. Campanati A, Penna L, Guzzo T, Menotta L, Silvestri $B$, Lagalla $G$, et al. Quality-of- life assessment in patients with hyperhidrosis before and after treatment with botulinum toxin: results of an open-label study. Clin Ther. 2003;25(1):298-308.

11. Schneier FR, Heimberg RG, Liebowitz MR, Liebowitz MR, Blanco C, Gorenstein LA. Social anxiety and functional impairment in patients seeking surgical evaluation for hyperhidrosis. Compr Psychiatry. 2012;53(8):1181-6.

12. Ramos R, Moya J, Turón V, Pérez J, Villalonga R, Morera $R$, et al. [Primary hyperidrosis and anxiety: a prospective preoperative survey of 158 patients]. Arch Bronconeumol. 2005;41(2):88-92. Spanish.

13. Ruchinskas RA, Narayan RK, Meagher RJ, Furukawa $\mathrm{S}$. The relationship of psychopathology and hyperhidrosis. Br J Dermatol. 2002;147(4):733-5.

14. Álvarez PDA. Hiperhidrosis primaria, simpatectomía y sudoración compensadora. Rev Patol Respir. 2005;8(4):335-7.
15. Lyra RM, Campos JRM, Kang DWW, Loureiro MP, Furian $M B$, Costa MG, et al. Diretrizes para a prevenção, diagnóstico e tratamento da hiperidrose compensatória. J Bras Pneumol. 2008;34(11):967-77.

16. Stefaniak TJ, wigo $\square$ M. Long-term results of thoracic sympathectomy for primary hyperhidrosis. Pol Przegl Chir. 2013;85(5):247-52.

17. Baroncello JB, Baroncello LRZ, Schneider EGF, Martins GG. Evaluation of quality of life before and after videothoracoscopic simpathetomy for primary hyperidrosis. Rev Col Bras Cir. 2014;41(5):325-30.

Received in: 16/06/2016

Accepted for publication: 04/09/2016

Conflict of interest: none.

Source of funding: none.

\section{Mailing address:}

Luciara Irene de Nadai Dias

E-mail: ftludenadai@gmail.com 